\title{
A ausência do celibato na cidade de Goiás no século XIX concupiscência e pecado*
}

\section{The absence of celibacy in the city of Goiás in the nineteenth century \\ lust and sin}

MARIA DA CONCEIÇÃo SILVA

Professora no Departamento de História da UFGO

Doutora em História/UNESP/Franca/SP

Campus II-FCHF/UFG

mariacsgo@yahoo.com.br

RESUMO A presente pesquisa analisa dois testamentos-cerrados escritos, no século XIX, por padres que reconheceram sua prole, direcionaram suas heranças e, ainda, reconheceram as "faltas graves" que cometeram. O importante é notar que esses eclesiásticos usufruíram da razão jurídica para fazer a legitimação de paternidade dos filhos em testamento, que permanecera lacrado. Certamente, os padres sabiam que o documento (testamento) se tornaria público após a confirmação do óbito do testador. Desse modo, o fato de os filhos serem furtos de transgressão ao celibato não causaria nenhum constrangimento ao exercício religioso do pai.

Palavras-chave testamentos, celibato, pecado

ABSTRACT The present research analyzes two closed written testaments for priests, in century XIX, that recognized its offspring, addressed their

Artigo recebido em 28/06/2008. Aprovado em 03/03/2009. 
inheritances and, yet, recognized the serious faults that committed. The important is to notice that these ecclesiastical enjoyed of the juridical reason to make the sons paternity legitimation in testament, that had remained sealed. Certainly, the priests knew that the document (testament) would become public after the testator death confirmation. Thus, the fact of the sons are transgression fruits to the celibacy would not cause any constraint to the father's religious exercise.

Keywords testament, celibacy, offense

\section{Testamentos e investigação histórica}

No Brasil, testamentos-cerrados são importantes documentos que permitem ao testador fazer a direção de bens, o reconhecimento de filhos considerados naturais (bastardos), etc, e, assim, registram-se os desejos pós-mortem, sobretudo os que não poderiam ser socializados em vida, a exemplo dos dois testamentos aqui investigados. Cabe, portanto, ressaltar que esse tipo de documento foi a maneira escolhida para justificar algumas ações privadas, notadamente, as amorosas que, muitas vezes, não poderiam ser socializadas ou se poderiam, pelo menos, na certidão de nascimento, jamais o nome do pai era declarado. Ocultaram-se, então, informações que publicizassem situações como a condição de paternidade de pessoas nascidas de relações ilícitas. Para o estudo desse acervo documental, o pesquisador pode lançar mão de métodos que Ihe permitam focalizar a história das populações em diferentes espaços. Para tanto, métodos, como o quantitativo ou demográfico ${ }^{1}$ ou os da história cultural ou das idéias, têm sido utilizados para análises da história da família, da riqueza, entre outros temas. Dependendo da metodologia, exige-se "constituir o fato histórico em séries temporais de unidades homogêneas e comparáveis, e desse modo poder medir a evolução por intervalos de tempos dados, geralmente anuais", ${ }^{2}$ ou mesmo, por intervalos curtos. Nas últimas décadas, os demográficos e os estudiosos da história da família, da riqueza, da escravidão entre outras temáticas, têm optado por trabalhar com documentos que permitam os caminhos da quantificação e, como isso, mostrem o avanço nas pesquisas. Descobriram que esses documentos (testamentos, censos de população, registros de nascimentos, casamentos, etc.) trazem à luz importantes informações que permitem inferir problemáticas de determinada população em um tempo e lugar próprios. Todavia, vale explicar que,

1 Para esse tipo de pesquisa é preciso montar um banco de dados com informações que permitam o cruzamento delas.

2 FURET, François. O quantitativo em história. In: LE GOFF, Jacques; NORA, Pierre. História: novos problemas. Tradução Theo Santiago. 3.ed. Rio de Janeiro: F. Alves, 1988. p.51. 
no caso desta pesquisa, com apenas dois testamentos, optamos por não organizá-los em séries para possíveis quantificações demográficas e posteriores investigações.

Para a organização de um banco de dados, requer-se um acervo maior de testamentos ou de outros documentos que possam ser quantificáveis. Se os testamentos tornaram-se fontes importantes para a análise da vida familiar, da composição da riqueza de famílias, do reconhecimento de filhos bastardos, nesta pesquisa cabe, portanto, explicitar a problemática suscitada nos dois testamentos-cerrados; a primeira é averiguar a história da família, as relações sociais dos autores dos documentos, Antonio Pereira Ramos Jubé e José Iria Xavier Serradourada. A segunda hipótese é entender a posição da Igreja goiana a respeito do cumprimento do celibato, uma vez que os testamenteiros (sacerdotes em Goiás) fizeram o reconhecimento de vários filhos.

Para entender as ações dos dois eclesiásticos, deixadas nos seus escritos oficialmente lacrados e guardados em poder dos próprios testamenteiros, compartilhamos de investigações como as de Maria Lucília Viveiros Araújo que afirma ser o testamento um tipo de escritura particular (pública ou sigilosa) que surgiu para orientar a vida familiar e os direitos de sucessão na América Portuguesa. No Brasil, o costume de escriturar bens e direcioná-los, via testamento, foi prescrito, inicialmente, nas Ordenações Filipinas de 1603, que vigoraram com algumas alterações, até a aprovação do Código Civil em 1916. ${ }^{3}$ Além disso, para a análise que aqui se propõe com testamentos é pertinente corroborar teses como as de Certeau e de Furet entre outros, de cujos estudos apreendem-se as entrelinhas: "lugar que torna possível determinada pesquisa, por meio de conjunturas e problemáticas comuns". ${ }^{4}$

Vale salientar que os testamentos-cerrados dos padres Antonio Pereira Ramos Jubé e José Iria Xavier Serradourada não foram escritos no mesmo ano, apesar de eles terem sido contemporâneos no exercício da função religiosa. O primeiro era vigário em Ouro Fino, município da capital de Goiás, e o segundo, cônego na capital. Os seus testamentos receberam o consentimento do tabelião de notas da cidade, que os finalizou lacrando-os com cerra e linha. Tanto as falas quanto os desejos dos dois reverendos permaneceram em silêncio até a confirmação de seus óbitos, momento adequado para a publicização do conteúdo (ou do sigilo) a respeito de suas vidas como clérigos e, notadamente, do reconhecimento de paternidade dos filhos. As particularidades da vida privada, portanto, induziam indivíduos a

3 ARAÚJO, Maria Lucília Viveiros. Contribuição metodológica para a pesquisa historiográfica com os testamentos. http://w.historica.arquivoestdo.sp.gov.br/matérias/anteriores/edicaçao06/materia01/texto01.pdf. acesso em: 23 de outubro de 2006, p. 1.

4 CERTEAU, Michel de. A operação histórica. In: LE GOFF, Jacques. História: novos problemas, p.27. 
ações como as escritas nos dois documentos, somente, revelados quando os seus autores já haviam falecido. Ao que parece, a população da cidade de Goiás (capital do estado até a década de 1930) convivia normalmente com os filhos dos padres. Neste caso, o conteúdo principal nos dois testamentos nos leva a crer que a legitimação de paternidade dos filhos dos clérigos é o significado da compartimentalização da vida privada, ou seja, a condição social obriga o indivíduo a tomar posições como assim fizeram os dois eclesiásticos. Em registros de batismo ou de nascimento a pessoa não reconhecida pelo pai como sendo filho legítimo é considerado "natural".

No caso dos dois eclesiásticos, a opção à vida sacerdotal, um tipo de trabalho, legitima ações de silêncio aos acontecimentos da vida privada, de seus de amores, cujos frutos foram o nascimento dos filhos. Nos dois testamentos-cerrados é possível que o reconhecimento dos filhos tenha sido o caminho para manifestar a paternidade (silenciada) e, ao mesmo tempo, o único meio para exteriorizar o que lhes foi imposto pela religião.

No Brasil, padres viviam publicamente amancebados, sem serem incomodados pela sociedade ou pelas autoridades eclesiásticas (bispos). Nesse sentido, os dois documentos trazem importantes contribuições para a compreensão das regras da Instituição, a respeito da sexualidade para as pessoas que optassem pela carreira eclesiástica. ${ }^{5}$ Nos manuscritos que aqui se investigam é possível averiguar o desejo exteriorizado pelos dois eclesiásticos, de reconhecimento dos filhos e, além disso, o direcionamento de seus bens, o pedido de perdão dos pecados praticados quando do exercício da fé cristã. Algumas indagações bastante curiosas podem ser aventadas a respeito da castidade como norma eclesiástica e a ausência à menção às mães de seus filhos. A pesquisa de Lewcowicz revela que:

Muitos clérigos, igualmente preocupados com o futuro de seus descendentes, legitimaram-nos em testamentos, que se constituem em fontes bastante precisas para a reconstituição da vida familiar dos padres nos séculos passados. Através desse tipo de documentação é possível conhecer o relacionamento dos religiosos com seus próprios filhos, mas em menor escala com as mulheres que os geraram. A maioria dos testamentos, embora procedendo o reconhecimento dos filhos, silenciava no que concernia às mães. ${ }^{6}$

Clérigos de várias regiões do país fizeram testamentos para legitimarem filhos. Percebemos que os padres goianos não foram os únicos que se apropriaram da lei para a legitimação de filhos por meio de testamentos.

5 Em 1215, no IV Concílio Lateranense reiterou-se as proibições à prática sexual e as chamadas à castidade. Todavia, foi no Concílio de Trento que a Igreja determinou a proibição da prática sexual aos eclesiásticos. A castidade passava a ser um valor que tinha que ser assumido por todos aqueles que quisessem acender ao estado clerical, sendo a abstinência sexual a sua conseqüência na prática. MARTÍNEN DOMINGUEZ, José Antonio. Os clérigos na Idade Média. Galizia: Editorial Toxosoutos/série Trivium, 2001, p.25-30. (tradução nossa).

6 LEWKOWICZ, Ida. A fragilidade do celibato. In: LIMA, Lana Lage da Gama. Mulheres, adúlteros e padres. Rio de Janeiro: Dois pontos, 1987, p.63. 
Assim, concordamos com a observação da pesquisadora acerca do silêncio quanto às mães de filhos de padres; pois os dois testamenteiros da cidade de Goiás nada relatam a respeito das mães de seus filhos.

\section{O teor dos dois testamentos-cerrados}

O primeiro é um testamento-cerrado do padre Antonio Pereira Ramos Jubé, escrito em 5 de março de 1885, encontrado entre os seus bens no arrayal de Ouro fino, e apresentado ao juiz de direito da comarca de Goiás, Manoel Lopes de Carvalho Ramos, em 15 de outubro de 1896. Este magistrado certifica o óbito de Antonio Pereira Ramos Jubé ocorrido, no dia 29 de setembro de 1896, às 7 horas da noite, na cidade de Goiás e, em seguida, profere a solenidade e abertura do documento, o testamento-cerrado. ${ }^{7}$ No ano de 1896, havia transcorrido mais de uma década que Antonio Pereira Ramos Jubé, redigiu o seu testamento e no mesmo dia (5 de março de 1885) compareceu ao cartório da cidade de Goiás, acompanhado pelo capitão Luiz Nunes da Silva, capitão Francisco de Arruada Fialho, Firmo Francisco de Paula e Manoel Xavier da Silva; para solicitar ao tabelião, José da Costa Xavier de Barros, o aferimento do seu anseio como testador do documento apresentado. O testamento de Antonio Pereira Ramos Jubé foi escrito em 1885, quando ele estava com 66 anos de idade, torna-se impossível suscitar as hipóteses que o levaram a redigir o documento nessa data e com essa idade. Todavia, é importante analisar o teor do documento que, por sua vez, revela acontecimentos importantes de sua vida como clérigo.

O segundo documento também é um testamento-cerrado do presbítero secular da Ordem de São Pedro e vigário colado na Freguesia de Santa Anna da Capital, José Iria Xavier Serradourada, escrito em 12 de julho de 1898. Este padre veio a óbito no dia 4 de setembro de 1898, às 8:30 horas da manhã em sua residência à rua das Pedras, na cidade de Goiás, com 67 anos de idade. ${ }^{8}$ Além desses dois testamentos há também o óbito de um filho de outro importante eclesiástico, monsenhor Joaquim de Azevedo, padre na capital de Goiás. Os dois testamentos contêm informações importantes acerca da unanimidade dos dois padres, notadamente em suas ações de reconhecimento de paternidade dos filhos tidos quando exerciam a vida eclesiástica. Se os testamentos-cerrados tiveram importância para a legitimação paterna de filhos dos padres, cabe indagar porque os documentos escritos por bispos goianos não mencionam nenhum tipo de repressão ao comportamento desses clérigos em Goiás. Nesse sentido, as dúvidas são muitas a respeito do tratamento dispensado aos casos amorosos desses clérigos e de outros por parte da Igreja. Se, de fato, os seus superiores

Termo de abertura, p. 4-5, anexo ao testamento de Antonio Pereira Ramos Jubé.

8 Cidade de Goiás. Arquivo Frei Simão Dorvi. Testamento de José Iria Xavier Serradourada. 
eclesiásticos tinham conhecimento da ausência do celibato em Goiás, por que não tomaram nenhuma medida?

Os dois padres, Antonio Pereira Ramos Jubé e José Iria Xavier Serradourada, quando escreveram seus testamentos, já se encontravam em idade avançada ou doentes. O primeiro faleceu aos 77 anos de idade, e o segundo aos 67 anos. Pode-se suscitar que eles reconheceram os filhos já velhos e apropriaram-se da razão oferecida pela lei, uma vez que seus testamentos foram cerrados (lacrados) em cartório. Desse modo, a legitimação de paternidade explicitada nos documentos somente se tornaria público após o falecimento dos testamenteiros, fato que os dois padres sabiam.

O testamento-cerrado era um direito de lei usufruído por muitas pessoas que registravam acontecimentos importantes de suas vidas, uma vez que o sigilo de seus depoimentos era assegurado, e eles somente se tornariam público após a comprovação do óbito do testador. No final do documento se anexava um atestado do tabelião aprovando a veracidade do mesmo, bem como o perfeito juízo do autor (testador). Nesse sentido, é possível que os padres, Antonio Pereira Ramos Jubé e José Iria Xavier Serradourada, utilizaram dessa legislação para o reconhecimento de seus filhos, direcionando-Ihes os bens que possuíam, além de incumbi-los de algumas tarefas.

Antonio Pereira Ramos Jubé e José Iria Xavier Serradourada, ainda, registraram nos testamentos faltas, que consideravam graves, afirmando que haviam cometidos alguns pecados contra Deus e a Igreja Católica. Se o reconhecimento de filho e a direção de bens eram feitos em testamento-cerrado, que permaneciam em completo sigilo até se confirmar o óbito do testador, algumas hipóteses podem balizar esta pesquisa. Entre elas, a forma solene e, muitas vezes, angustiante de pessoas que esperavam a abertura do documento, sobretudo os envolvidos, sejam indiretamente ou diretamente, como as esposas traídas pelos maridos ou os filhos ilegítimos que descobriam a verdade somente na abertura do testamento. Certamente, muitos filhos não puderam desfrutar da companhia do pai, muitas mulheres foram menosprezadas pelos maridos que mantinham concubinas ou pelos que se dedicavam à religião, tornando-se eclesiásticos. É possível que nos escritos testamentais existam muitas histórias silenciadas, muitos casos em que a esposa, sendo a legítima mulher, apenas tomara conhecimento da deslealdade conjugal após o óbito do marido, na abertura e leitura do testamento.

Seguindo o protocolo legal, o juiz da comarca de Goiás, de posse do testamento-cerrado de Antonio Pereira Ramos Jubé, e ao confirmar-se o seu óbito, procedeu à abertura solene do documento, convocando as partes citadas (nomes) para cumprirem a decisão do testador tomada em 1885. O padre além de reconhecer os seus filhos, fazer a partilha de seus bens, revela parte da sua trajetória de vida, como, por exemplo, o seu cotidiano 
como vigário da paróquia de N. S. de Pilar de Ouro fino da capital de Goiás. O documento contém verdadeira riqueza de informações, no início exterioriza a sua crença do testamenteiro aos ensinamentos da Igreja Católica e, por conseguinte, solicitara o perdão dos seus pecados, encomendando a sua alma e determinando como deveria ser o seu funeral, as missas que deveriam se celebrar em seu nome depois de sepultado. Após a exposição de sua vida, ainda, fez a declaração de sua identidade paterna, relacionando os nomes de seus pais e, em seguida, pronunciando a quantidade de filhos, os seus nomes e os de suas mães. O curioso é que a respeito das mães de seus filhos, o padre pouco relatou e, assim, concluiu o documento com uma declaração de perdão, assumindo sua culpa e seu desvelo à desobediência cristã. O teor de seus escritos induz o leitor a imaginar que o exercício eclesiástico tocara em seu coração, fazendo refletir algumas ações de sua vida e as considerou como pecado, talvez a quantidade de missas solicitadas por ele, em intenção a sua alma, justificasse ou minimizasse as faltas ou os pecados cometidos.

Além deste do testamento localizou-se o registro de óbito de Jubé e outros documentos. O seu óbito foi assinado pelo cônego José Iria Xavier Serradourada.

Aos vinte e nove dias do mês de setembro de mil oitocentos e noventa e seis, na parochia de Sant'Ana da cidade de Goyaz faleceu da vida presente o Padre Antonio Pereira Ramos Jubé, de idade de setenta e sete anos, natural de Porto Nacional, vigário collado da Parochia de Nossa Senhora do Pilar de Ouro Fino, recebeu todos os socorros espirituais, jas no Cemitério. E para constar faço o presente.

O Cônego Cura José Iria Xavier Serradourada. ${ }^{9}$

O curioso é que no ano de 1896, quando faleceu Antonio Pereira Ramos Jubé, o padre José Iria Xavier Serradourada ainda não havia redigido o seu testamento, fazendo-o em 12 de julho de 1898. É possível que este padre soubesse do testamento-cerrado de Jubé e também resolveu se beneficiar da razão jurídica para reconhecer os seus filhos.

A transgressão ao celibato ainda é pesquisada por poucas pessoas, todavia são unânimes ao perceberem que em todas as partes do país, padres não respeitaram as normas da religião. Para Hugo Fragoso, "padres davam seu nome aos filhos, pois não eram eles simples 'bastardos', que só tivessem o sobrenome da mãe. Seus filhos deviam ser criados em igualdade de condições com as melhores famílias do lugar"10. Já Ida Lewkowicz ao pesquisar a fragilidade do celibato entre padres ressalta que

9 Cidade de Goiás. Arquivo Geral da Cúria Diocesana. Paróquia de Ouro Fino. Livro 2.

10 FRAGOSO, Hugo. A Igreja na formação do estado imperial. In: BEOZZO. (coord.) História da Igreja no Brasil. Petrópolis: Vozes, 1992. Tomo II/2, p.193. 
"o concubinato, a mancebia e a ilegitimidade não foram incomuns no meio eclesiástico"11. Outra estudiosa é Linda Lewin que investigou a ilegitimidade praticada pelo clero brasileiro e afirmou que os bispos fecharam os olhos para o problema, cumplicidade que significou um genuíno apoio à mancebia clerical' ${ }^{12}$. Talvez seja essa a posição adotada pelos bispos goianos, fecharam-se os olhos para o problema da mancebia eclesiástica, uma vez que muitos padres conviveram socialmente com os seus filhos como assim foi o caso dos padres de Goiás, Antonio Pereira Ramos Jubé e José Iria Xavier Serradourada, entre outros. Nesse sentido, notamos que a prole desses dois padres não se constituía de simples filhos ilegítimos. Todavia, vale ressaltar que muitos filhos bastardos foram privados do convívio de seus pais, sejam filhos de padres ou não.

O testamento-cerrado de Antonio Pereira Ramos Jubé prova que ao sentir-se já velho tentou amenizar sua culpa e traição à Igreja ou a sua consciência ao solicitar o perdão dos seus pecados, e determinar que, depois de morto, missas deveriam ser celebradas em seu nome e dos seus pais. Na verdade, o eclesiástico expõe a sua preocupação com a partida eterna e parece não se preocupar com o bem estar das mulheres envolvidas, apenas menciona os nomes delas como sendo mães de seus filhos. Transcreve-se aqui o testamento-cerrado de Antonio Pereira Ramos Jubé para que o leitor possa observar a riqueza de detalhes nestes escritos.

Em nome da Santíssima Trindade, Padre, Filho, Espírito Santo, três pessoas distinctas e um só Deos verdadeiro.

Eu Padre Antonio Pereira Ramos Jubé Vigário Collado na Parochia de Nossa Senhora do Pilar do Ourofino do Bispado de Goiáz natural da cidade do Porto Imperial da mesma Província de Goiáz estando em meu perfeito juizo, crendo, como verdadeiramente creio tudo que crê ensina e confessa nossa Santa Madre Igreja Catholica Romana, em cuja fé protesto viver e morrer, esperando da Divina Piedade o perdão dos meos pecados, e que me ha de salvar, obtorgo [sic] meo testamento e última vontade pela fórma seguinte: $1^{\circ}$ Encommendo minha alma a Deos, que a criou e a envio com o seo precioso sangue. Declaro que quero que meo Corpo seja enterrado na Igreja Matriz do Ouro fino, e que meo enterro seja acompanhado pelo menos de um sacerdote, e meo corpo encommendado com Missa de Corpo prezente no $1^{\circ}, 2^{\circ}, 7^{\circ}$ e $30^{\circ}$ dias de minha morte, alem de outras que a devem celebrar durante o méz e mais uma Missa por alma de meos pais, e outra para as de todos os meos parentes.

Declaro que sou filho legitimo do Tenente Coronel José Antonio Ramos Jubé e D. Urçula Pereira Valle: Qué tenho seis filhos; sendo uma Eufemia Marcellina Ramos Jubé tida com Maria Eufemia de Mello; quatro que são: Januaria Pereira Ramos Jubé, Urçula Pereira Ramos Jubé, Antonio Pereira Ramos Jubé, e Joaquim Rufino Ramos Jubé, tidos com Joanna Cordeira de Sant'Anna, e uma

11 LEWKOWICZ, Ida. A fragilidade do celibato, p.62.

12 LEWIN, Linda. Surprise heirs: illegitimacy, inheritance rights, and public power in the formation of Imperial Brazil, 1822-1889. Stanford/California: Stanford University Press, 2003, v.2, p.112. 


\begin{abstract}
Benedicta Pereira Ramos Jubé menor de três annos, havida com Maria Carolina da Conceição, que é natural da cidade da Uberaba (província de Minas). Declaro que mais nada devo ate esta data; e que da minha terça se faça o enterro e o remanecente seja applicado em suffragios a minha alma; e nomeio aos ditos seis filhos meos herdeiros, para que os herdem e gozem com a benção de Deos; para cumprirem este meo testamento nomeio para meos testamenteiros a Joaquim Ignacio da Silveira, Ayres Feliciano de Mendonça, meos genros e o meo filho Antonio Pereira Ramos Jubé, aos quaes dou todas as faculdades que como ataes concede o direito. E por este meo testamento escrevo e assinei lho outro qualquer que anterior tiver feito antes deste, que faço digo pois é o quero e é minha vontade que valha este, que faço na prezença das testemunhas que assignão no instrumento de approvação que adiante vai feito pelo official Publico. E por esta forma hei por findo este meo testamento de ultima vontade que assigno, cidade de Goiáz 5 de Março de mil oitocentos e oitenta e cinco. Pe - Antonio Pereira Ramos Jubé. (...). Registrado no livro próprio a folhas quatorze à quinze. Goyaz, 22 de Outubro de 1896. O Escrivão por designação - Luiz Antonio Pereira de Abreu. ${ }^{13}$
\end{abstract}

O testamento-cerrado do padre Jubé cumpria funções importantes como a de ocultar a desobediência aos votos de castidade, de legitimar os filhos e de direcionar os seus bens além de referendar a solicitação de perdão por suas faltas cometidas, faltas que não são explicitamente declaradas. Se o documento foi importante ao reconhecer os filhos, o pesquisador fica a imaginar: se os filhos, frutos de amores em silêncio, seriam as faltas cometidas pelo padre.

Junto ao testamento há um manuscrito intitulado Apresentação. Neste documento, o tabelião conferiu validade ao testamento-cerrado que, de imediato, fora lacrado e entregue ao testador. Após o seu óbito na cerimônia de abertura do testamento de Antonio Pereira Ramos Jubé, o escrivão relata que este se encontrava entre os seus pertencentes. A lei determina que o testamento-cerrado pode permanecer sob a guarda do testador até o seu falecimento, entretanto deve-se comprovar a sua veracidade com os lacres intactos, o documento deve estar fechado.

\title{
As relações do padre Antonio Pereira Ramos Jubé com os filhos
}

Ao comparar os registros de casamento dos filhos do padre Antonio Pereira Ramos Jubé com o seu testamento observamos que um de seus filhos casou-se em 1882 e o outro em 1890, antes de serem reconhecidos pelo padre como filhos legítimos, uma vez que o testamento fora escrito em 5 de março de 1885 e, somente, aberto após o seu falecimento em 29 de setembro de 1896. Até esta data os seis filhos foram considerados naturais, sendo eles: Eufemia Marcellina Ramos Jubé tida com Maria Eufe-

13 O documento encontra-se preservado na cidade de Goiás. Arquivo Frei Simão Dorvi. 
mia de Mello; quatro: Januaria Pereira Ramos Jubé, Urçula Pereira Ramos Jubé, Antonio Pereira Ramos Jubé e Joaquim Rufino Ramos Jubé, tidos com Joanna Cordeira de Sant'Anna; e uma: Benedicta Pereira Ramos Jubé tida com Maria Carolina da Conceição. Para a sociedade da época, ao que parece, não era segredo a existência de filhos de padres, entretanto ao serem batizados não recebiam o nome do pai e, por isso, muitos foram considerados filhos bastardos. Todavia é possível suscitar hipóteses acerca do cotidiano dos filhos desse padre na cidade de Ouro fino ou na capital de Goiás. Observa-se que os filhos não se ausentaram do convívio com o pai. Este esteve sempre presente em momentos importantes como, por exemplo, na celebração do batismo, de casamento. Na Matriz de N. S. do Pilar de Ouro fino, o pai realizou os batismos de Januaria Pereira Ramos Jubé, no dia 26 de março de 1850, ${ }^{14}$ de Ursula, no dia 15 de fevereiro de $1852,{ }^{15}$ e de Joaquim, no dia 31 de outubro de $1855,{ }^{16}$ Eufemia, no dia 2 de fevereiro de 1881, e o de Benedicta, no dia 24 de janeiro de $1883^{17}$ já outro filho, Antonio, foi batizado por Joaquim Vicente de Azevedo, no mês de outubro de 1856, sendo o celebrante padrinho juntamente com Ana Cordeiro de Sant'Ana. ${ }^{18} \mathrm{O}$ padre (pai) ainda foi testemunha de casamento de um de seus filhos. os filhos de Antonio Pereira Ramos Jubé receberam os principais sacramentos cristãos pelas mãos do próprio pai ou de seus colegas.

Nas Constituições Primeiras do Arcebispado da Bahia de 1707, a certidão de batismo era um documento escrito pelo vigário da paróquia em livros próprios, onde se celebrava esse sacramento. O registro de batismo era considerado certidão de nascimento até a aprovação da lei de Registro Civil dos Nascimentos, Casamentos e Óbitos, em 9 de setembro de 1870. Se os padres legitimassem seus filhos no ato da pia batismal, como ficariam os votos feitos para se tornarem sacerdotes. Tudo indica que isto não os impediu de conviver com os filhos, tendo ainda o apoio dos colegas de ministério que, por sua vez, participavam desse cotidiano, celebrando os batizados, casamentos e sendo testemunhas.

Os registros de casamentos dos filhos Eufemia Marcellina Ramos Jubé, Januaria Pereira Ramos Jubé, Antonio Pereira Ramos Jubé, Joaquim Rufino Ramos Jubé comprovam o convívio entre pessoas da cidade de Goiás, de padres celebrantes e colegas.

14 Cidade de Goiás. Arquivo Geral da Cúria Diocesana. Livro de batizados da Paróquia de Ouro Fino n.1, f.16.

15 Cidade de Goiás. Arquivo Geral da Cúria Diocesana. Livro de batizados da Paróquia de Ouro Fino n.1, f.22, n. 120 .

16 Cidade de Goiás. Arquivo Geral da Cúria Diocesana. Livro de batizados da Paróquia de Ouro Fino n.1, f.38, n.118.

17 Cidade de Goiás. Arquivo Geral da Cúria Diocesana. Livro de batizados da Paróquia de Ouro Fino n.2, f.7, n.46.

18 Cidade de Goiás. Arquivo Geral da Cúria Diocesana. Livro de batizados da Paróquia de Ouro Fino n.1, f.45. 
Em 1871, realizou-se o casamento de Eufemia Marcellina Ramos Jubé, neste enlace observamos o relacionamento social e o cumprimento religioso da família do padre:

Ao primeiro dia do mez de julho de 1871, na Matriz de N. S. do Pilar de Ouro fino, às 8 horas da manhã, em presença das testemunhas o capitão Antonio Augusto de Pádua Fleury e Dona Leonor Gertrudes Fialho dos Guimarães, ajuntou em casamento e deu as bênçãos nupciais ao Tenente Joaquim Ignácio da Silveira com dona Eufemia Marcellina Ramos Jubé. Filha natural de Dona Maria Eufemia de Mello; o noivo filho legítimo de José Ignácio da Silva e dona Joaquina Umbelino de [?]. ${ }^{19}$

A filha Januaria Pereira Ramos Jubé foi batizada no dia 26 de março de 1850, pelo pai Antonio Pereira Ramos Jubé, o seu matrimônio foi celebrado na Igreja de N. S. do Pilar de Ouro fino, onde o pai era vigário colado, pelo padre José Iria Xavier Serradourada. Nesse enlace foram testemunhas o major João Baptista da Silva e Eufemia Marcellina da Silveira Ramos Jubé. O padre José Iria Xavier Serradourada, celebrante do matrimônio, tinha conhecimento da paternidade da nubente, uma vez que era filha de seu colega vigário da Paróquia de Ouro fino. O registro de casamento evidencia que:

Em 06 de agosto de 1882, na Igreja de nossa senhora do Pilar da paróquia de Ouro Fino, às 10:00 horas da manhã, o padre José Iria Xavier Serradourada, celebrou com Intra Missam o matrimônio de Ayres Feliciano de Mendonça, viúvo de Dona Maria Rufina Coelho de Mendonça, e natural desta capital de Goyaz, filho legítimo de Manoel Joaquim de Mendonça e de Francisca Ramos Jubé, já falecidos, residente nesta Paróquia, com Dona Januaria Pereira Ramos Jubé, filha natural de Dona Joanna Cordeiro de Sant'Anna, nascida e residente na freguesia de Sant'Anna da capital de Goyaz. Foram testemunhas o major João Baptista da Silva e Dona Eufemia Marcellina da Silveira Ramos Jubé. Dispensados do Impedimento de consangüinidade no segundo grau igual da linha transversal..$^{20}$

No registro de batismo de Urçula Pereira Ramos Jubé, filha de Joanna Cordeiro de Sant'Anna, o pai celebrou esse sacramento no dia 15 de fevereiro de 1852. Outro filho (Antonio Pereira Ramos Jubé), tendo o mesmo nome do padre também se casou na Igreja de N. S. do Pilar de Ouro fino, sendo a cerimônia celebrada com missa (intra missam) por José Iria Xavier Serradourada. Neste registro aparece o nome do pai como escrivão.

Aos dezoito dias do mez de agosto de mil oitocentos e oitenta e nove nesta parochia Igreja de N. S. do Pilar de Ouro fino com presença das testemunhas

19 Cidade de Goiás. Arquivo Geral da Cúria Diocesana. Livro n.4, de casamentos da Paróquia de Sant'Anna, Cidade de Goiás. (grifo nosso).

20 Cidade de Goiás. Arquivo Geral da Cúria Diocesana. Livro n. 5, de casamentos da cidade de Goiás e de Ouro Fino, p.22/22v. (grifo nosso). 
Tenente Joaquim Ignácio da Silveira e Dona Ângela da Veiga Jardim com licença competente o cônego José Iria Xavier Serradourada recebeo em casamento com palavras de presente na forma do ritual romano e deo benção intra missam a Antonio Pereira Ramos Jubé e Maria da Providencia Ramos Jubé, e para constar fiz este assento. O vigário collado - Antonio Pereira Ramos Jubé. ${ }^{21}$

Já no matrimônio do filho de nome Joaquim Rufino Ramos Jubé, natural de Ouro fino de Goiás, o seu pai testemunhou o enlace juntamente com o capitão Joaquim Martins Xavier Serradourada e o frei Raymundo Maria Madré. No registro desse enlace pode-se ler que:

Em 15 de fevereiro de 1890, na Capela de N. S. do Carmo, às 5:00 horas, o padre Theodoro Linhares, celebrou o matrimônio de Joaquim Rufino Ramos Jubé, com 32 anos de idade, natural de Ouro Fino, filho natural de Dona Joanna Cordeira de Sant'Anna, com Dona Maria Carlota d'Assunção Silveira, 22 anos de idade, filha legítima do tenente Joaquim Ignacio da Silveira e de Dona Euphemia Marcellina da Silveira Ramos Jubé, nascida nesta cidade de Goyaz. Foram testemunhas o capitão Joaquim Martins Xavier Serradourada e o Reverendo Vigario Antonio Pereira Ramos Jubé, Frei Raymundo Maria Madré. Provisão do bispo diocesano de 12 do corrente mês. Foram dispensados de três proclamas e do impedimento de consangüinidade no $2^{\circ}$ grão attingente ao $1^{\circ}$ da linha collateral desigual..$^{22}$

No enlace, além de outro religioso o pai também foi testemunha de casamento do filho. Desse modo, é público o não-cumprimento das regras católicas por esses eclesiásticos, os filhos frutos da transgressão à castidade (ou do pecado como assim disse Antonio Pereira Ramos Jubé em seu testamento) participam do seu convívio no Arrayal de Ouro Fino, município de Goiás. O curioso é que os nomes de suas mães não são mencionados, claro que, pelo menos, na pia batismal elas se fizeram presentes, nos enlaces é difícil aventar alguma possibilidade acerca da presença delas.

Em nenhum documento pastoral, os bispos goianos mencionaram o comportamento inadequado do clero que teve filhos. Se, por um lado, o silêncio dos bispos objetivava a defesa da lgreja, por outro lado, a sociedade não excluía os padres e os seus filhos do recebimento dos principais sacramentos e certamente de outros eventos sociais.

Nesse sentido, os dois testamentos tratam do reconhecimento e legitimação de filhos de dois importantes eclesiásticos da cidade de Goiás. Nestes documentos nos chama à atenção a verdadeira riqueza de detalhes acerca da vida dos testamenteiros. Entre tantos detalhes importantes um deles é a assinatura do escrivão - Joaquim Rufino Ramos Jubé - filho do padre que o reconheceu por meio de testamento escrito em 1885. O filho de

21 Cidade de Goiás. Arquivo Geral da Cúria Diocesana. Livro 1 de casamentos da Paróquia de Ouro Fino, p.20v.

22 Cidade de Goiás. Arquivo Geral da Cúria Diocesana. Livro 1 de casamentos da paróquia de Ouro Fino, p.24. 
Antonio Pereira Ramos Jubé tornou-se escrivão, cargo de relevância para a região. Outros fatos do convívio particular são importantes.

Nos escritos testamentais do padre José Iria Xavier Serradourada os seus filhos também foram legitimados em testamento-cerrado como pode haver tantos outros nessas mesmas condições.

\section{Testamento do padre José Iria Xavier Serradourada}

É relevante observar no testamento desse clérigo a ausência do celibato e, além disso, a sua resignação e fé ao catolicismo. Este documento é ainda mais rico em detalhes do que o do padre Antonio Pereira Ramos Jubé. Para tanto, transcrevemo-lo integralmente:

Em nome da Santíssima Trindade, Padre, Filho, Espírito Santo, em quem eu José Iria Xavier Serradourada, firmemente creio, e em cuja fé protesto viver e morrer. Estando enfermo mas em meu perfeito juízo e temendo a morte, cujo dia é incerto; determinei fazer este meu testamento, para dispôr dos poucos bens que possuo e o faço pela maneira seguinte: $1^{\circ}$ Declaro que sou Catholico Apostólico e Romano, Natural d'esta cidade, filho legitimo de Bazilio Martins Braga Serradourada e sua mulher Dona Anna Maria Violante Xavier, já falecidos, e que sou Presbítero Secular da Ordem de São Pedro, Vigário Collado da Freguesia de Santa Anna d'esta capital, Geral do Bispado no estado, e presentemente governador do Bispado n'este mesmo estado. $2^{\circ}$ Declaro que por fraqueza humana tive uma filha de nome Benedicta, com Maria Joaquina da Rocha e um filho de nome Benedicto, com Norberta da Silveira Borges, ambos solteiros; cujos meus filhos existem vivos n'esta capital, estimando-me e respeitando-me com todo o affecto e carinho; e como não os tivesse ainda sido reconhecidos, os reconheço por meus filhos por meio d'este testamento e de conformidade com as leis que regem esta matéria. $3^{\circ}$ Possuindo eu duas cazas n'esta cidade, a saber: uma na rua Doutor 'Couto' antiga do Carmo de número dezessete, entre, as cazas de Dona Anna Joaquina Milameixas e os orphãos filhos do fallecido Germano Renovato dos Santos; e uma outra na rua 3 de Maio, antiga 'Campo da Forca', sob numero dezesseis, entre as cazas de de Dona Maria Maria Luiza do Nascimento Santos e dos orphos filhos de José Lemes Borges; dellas faço doação, a saber: á da rua 'Doutor Couto', á minha filha Benedicta Xavier Serradourada, e a da rua 3 de Maio, a meu filho Benedicto Sabino Xavier Serradourada, das quaes poderam elles donatários gozar cada uma a sua, que ficam sendo, depois de minha morte. $4^{\circ}$ Instituo por meus únicos herdeiros os referidos meus filhos Benedicta e Benedicto os quaes, herdarão os meus poucos bens, herdarão os meus poucos bens, em egualdade em valor, embora sejam esses poucos bens de pouco valor, mormente os Movéis que se achão estragados. $5^{\circ}$ Deixo os meus papeis de (sic) a Cathedral, ficando porém incumbida de guradarl-ar e zelal-as, o meu mano João Baptista Xavier Serradourada, a fim de que não ser extravieese e que possão perdurarem pelo tempo que fôr possível. $7^{\circ}$ Recommendo e tenho por mui recommendado, que o meu enterro se faça sem pompa de fórma alguma dispensando, corôas, grinaldas com fitas e lettraes douradas; devendo o meu caixão ser fourado de chita preta e nastro preto, dispensando ainda gallões e outros quaesquer luxo. $8^{\circ}$ Nomeio os meus testamenteiros em $1^{\circ}$ logar meu irmão joaquim Martins Xavier Serradourada; em $2^{\circ}$ meu irmão João Baptista 
Xavier Serradourada e finalmente em $3^{\circ}$ logar a meu irmão Antonio Martins Xavier Serradoura aos quaes pela muita amizade e união em que sempre vivemos, e por essa mesma amizade e união peço que acceitem este encargo Pio, aps quaes encarrego o meu enterro. E por este modo e f'roma tenho concluído este meu testamento e ultima vontade, que fiz muito expontaneamente e sem induzimentode pessâo alguma; elle vai escripto a meu pedido por Luiz Antonio Pereira de Abreu, e somente por mim assignado; peço pois as autoridades do meu Paiz o cumprão, e mandarem cumprir, tão inteiramente como n'elle se contem. Goyaz, 12 de Julho de 1898. Cônego José Iria Xer. Serradourada. ${ }^{23}$

No documento, o testamenteiro justificou o motivo pelo qual estava legitimando os filhos da seguinte maneira: "como não os tivesse ainda sido reconhecidos, os reconheço por meus filhos por meio d'este testamento e de conformidade com as leis que regem esta matéria". O reconhecimento de paternidade via testamento ocorreu quando o padre estava doente e "já temendo a morte", que declarou "não ter até o momento reconhecido os seus filhos" e, ainda, fez a divisão dos seus bens entre os dois filhos. A cada filho coube a herança das casas de propriedade de José Iria Xavier Serradourada, todavia os bens declarados comprovam uma vida modesta, parece não ter gozado de nenhuma fortuna.

Por um lado, o documento é importante ao explicitar o desejo de reconhecimento de paternidade dos filhos, por outro lado, a manifestação de pecado contra a Igreja, uma vez que o testador pediu perdão declarando: "que por fraqueza humana" tivera os filhos e ainda ressaltou grande afeto pelos mesmos, ao afirmar que os filhos os estimava e respeitava "com todo o affecto e carinho", apesar da honestidade ao fazer o reconhecimento de sua prole, o testamento-cerrado revela a existência de práticas concupiscênciosas por eclesiásticos, membros da Instituição católica que, por sua vez, deveriam zelar pela aplicabilidade das normas aprovadas em concílios.

Desse modo, os testamentos dos dois padres, o atestado de óbito do filho do monsenhor Joaquim Vicente de Azevedo ${ }^{24}$ e tantos outros como o "Testamento n.228/1868", de "Izabel Francisca de Souza" transcrito na obra História de Niquelândia.

Declaro que sou Catholica Romana, nascida e batizada na Villa de Nossa Senhora de Natividade, pertencente a este bispado (...) sendo filha legítima de Manoel de Souza de Azevedo e de sua mulher Dona Maria José Correia de Araújo, já falecidos a muitos anos'. Foi casada com o cap. João Nicolau da Silva e tiveram Antônio Nicolau da Silva, já falecido naquela data. Sucessores, as netas Izabel

23 Cidade de Goiás. Arquivo Frei Simão Dorvi. Testamento-cerrado do padre José Iria Xavier Serradourada.

24 Atesto que faleceu hontem a noite as $93 / 4$ horas Antonio Candido de Azevedo, com 34 annos de idade, filho legitimo do falecido Monsenhor Joaquim Vicente de Azevedo sendo sua mãe Messias Xavier de Barros, de enfermidade, como febres, rheumatisma, e outras. Goyaz, 26 de dezembro de 1899. Guias das pessoas sepultadas no cemitério público desta cidade. Documentos do Hospital Pedro de Alcântara, preservado na cidade de Goiás. Arquivo Frei Simão Dorvi. 
Joaquina Rosa da Silva (c/c. Benício José Taveira), Genoveva Joaquina Rosa (c/c Joaquim Vicente de Azevedo) e Joana Rosa da Silva, filhos de 'minha falecida comadre Joaquina Rosa da Silva'. Quer que sua bisneta Tereza, residente em Couros seja herdeira, pois não pode ser reconhecida por seu neto Padre Nazário Antônio da Silva. Por testamenteiro, seu afilhado o Cap. José Joaquim Francisco da Silva. Deixou 10 contos, além das fazendas Engenho e Morro Redondo. (Analfabeta. Riquíssima para a época). ${ }^{25}$

São acervos importantes, pois trazem informações acerca das transgressões ao celibato. Desses, duas questões merecem algumas análises: a primeira é específico à afirmação do padre José Iria Xavier Serradourada - pela fraqueza humana- e, segundo, o celibato como regra da Instituição aprovada no Concílio de Trento. Em particular, os dois documentos dos dois padres da cidade de Goiás e, por fim, tantos outros são a prova da "fragilidade do celibato" ou da ausência de castidade apontada por alguns estudiosos.

Pelos testamentos analisados conclui-se, que, de fato, a alta cúpula da lgreja manteve-se em silêncio a respeito do comportamento de muitos padres. Cabe, portanto, perguntar: quantos filhos de padres continuaram sendo filhos ilegítimos? Para obter a resposta faz-se necessário vasculhar os documentos deixados por eclesiásticos a exemplo dos dois testamentos-cerrados e de tantos outros guardados em arquivos. 